Eurasian Journal of Physics and Functional Materials

$2021,5(2), 155-162$

\title{
The influence of pulse-plasma treatment on the phase composition and hardness of $\mathrm{Fe}-\mathrm{TiB}_{2}-\mathrm{CrB}_{2}$ coatings
}

\author{
A.B. Kengesbekov ${ }^{1}$, B.K. Rakhadilov ${ }^{1}$, Yu.N. Tyurin ${ }^{2}$, \\ N.M. Magazov*,1, M.K. Kylyshkanov ${ }^{3}$, Zh.B. Sagdoldina ${ }^{1}$ \\ ${ }^{1}$ S. Amanzholov East Kazakhstan University, Ust-Kamenogorsk, Kazakhstan \\ ${ }^{2}$ E.O. Paton Electric Welding Institute, Kiev, Ukraine \\ ${ }^{3}$ JSC UMP, Ust-Kamenogorsk, Kazakhstan \\ E-mail: magazovn@mail.ru
}

DOI: 10.32523/ejpfm.2021050209

Received: 27.05.2021 - after revision

\begin{abstract}
This work are presented the research results of pulse plasma treatment influence on the phase composition, hardness, roughness and element composition of coatings on the bases of $\mathrm{Fe}_{-}-\mathrm{TiB}_{2}-\mathrm{CrB}_{2}$. The $\mathrm{Fe}-\mathrm{TiB}_{2}-\mathrm{CrB}_{2}$ coating was deposited by detonation method. The following pulse-plasma treatment was used to modify the structure and properties of the surface layers of the sprayed coating. The results of mechanical experiments showed that the hardness of $\mathrm{Fe}-\mathrm{TiB}_{2}-\mathrm{CrB}_{2}$ coating increased after the treatment. On the basis of the X-ray analysis, it has been established that the increase of coating hardness is connected with phase transformations in a surface layer, in particular, with formation of oxide phases and increase of carbide particles quantity.
\end{abstract}

Keywords: coating, detonation spraying, pulse-plasma treatment, hardness.

\section{Introduction}

One of the main problems of modern aviation industry is to improve the quality, reliability and durability of parts, units and mechanisms. Traditionally used 
structural materials and alloys cannot effectively resist destruction during operation and retain the original level of properties. Development of materials for such parts is complicated by harsh operating conditions: high cyclically changing temperatures, dynamic nature of load mode changes, aggressiveness of highspeed gas flow consisting of fuel combustion products. This problem can be solved by applying effective methods of manufacturing, restoration and hardening of machine parts by applying special materials that ensure obtaining coatings with the specified physical and mechanical properties [1, 2]. Such materials, in terms of price and quality, can be powder three and more component eutectic alloys on the bases of iron with refractory borides [3-5]. One such example is a coating based on $\mathrm{Fe}-\mathrm{TiB}_{2}-\mathrm{CrB}_{2}$. The structure of these alloys is formed by the introduction phases, borides, which form a framework that is filled with an iron matrix. The soft iron matrix transmits and redistributes stress between the individual branches of the hard, solid framework. Thus, in the cast eutectics under consideration, the mechanism of composite hardening is realized. High strength and tribotechnical properties in a range of temperatures up to $0.9 \mathrm{~T}_{\mathrm{pl}}$ $\left(900-1100^{\circ} \mathrm{C}\right)$ are caused by this condition of alloys [6, 7].

The coatings on the bases of $\mathrm{Fe}^{-} \mathrm{TiB}_{2}-\mathrm{CrB}_{2}$ are deposited by various gasthermal spraying processes, such as HVOF, cold spraying, detonation gun spraying, atmospheric plasma spraying and others. However, the coatings obtained by these methods have a number of drawbacks: low hardness and wear resistance of the coating surface, the presence of pores in the coating [3, 8], which cannot meet the demand for a long service life of the workpiece. Various methods of surface modification, such as plasma treatment, ion, electron and laser irradiation, etc., can be applied to improve these coating properties $[9,10]$. Among such coating modification methods, pulsed plasma treatment (PPT) is of particular interest [11].

In view of the above, the purpose of this work is to study the effect of pulse-plasma treatment on the phase composition and hardness of $\mathrm{Fe}-\mathrm{TiB}_{2}-\mathrm{CrB}_{2}$ coatings.

\section{Materials, equipment and research methods}

This work was made and investigated the protective coatings from powder of eutectic alloy HTN-23 based on iron with titanium and chromium diborides. The alloy composition (wt.\%): Fe-base; Ni $6 \div 8$; Cr $20.0 \div 20.5$; Ti $2.4 \div 2.5$; B $2.5 \div 2.6$; Al 5.6. The coating is applied by using a multi-chamber detonation unit (MCDU) [12, 13], where the powder material is heated and accelerated by the products of detonation combustion of a combustible gas mixture consisting of propane-butane, oxygen, and air. The coating equipment consists (Figure 1) of a multi-chamber detonation unit for spraying-1; a powder feeder-2; a gas console for feeding the combustible mixture-3; a process control system-4; an automated system for moving the detonation device-5. 


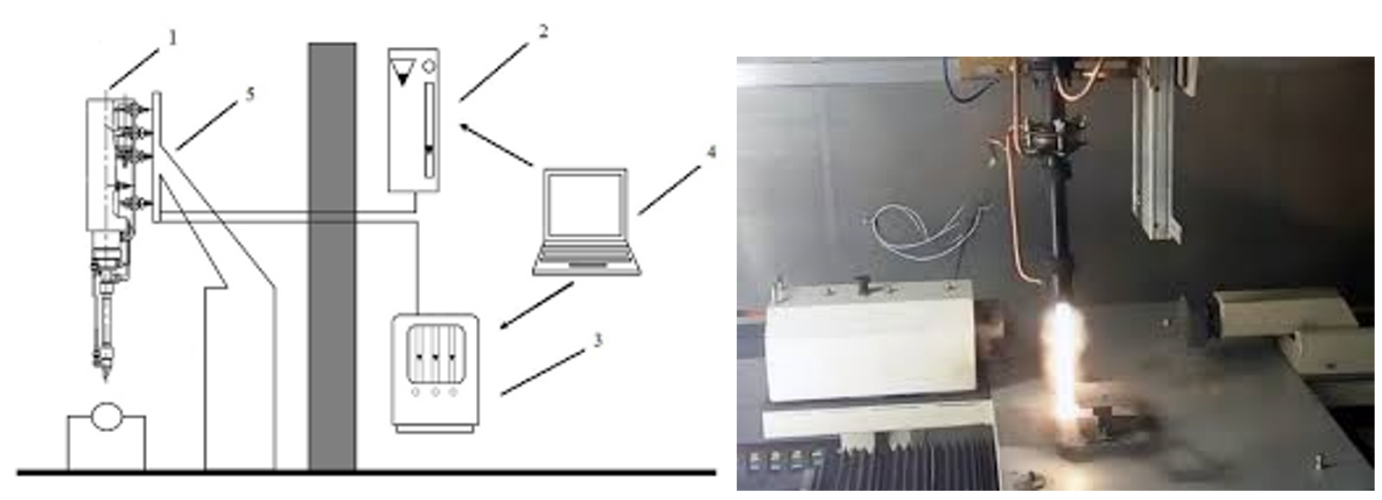

Figure 1. Equipment for coating with MCDU using: a-scheme of the unit; b-appearance of the unit during operation.

The MCDU implements compression detonation combustion of the gas mixture in specially profiled chambers. Accumulation of combustion energy from two chambers in a cylindrical barrel provides formation of a high-speed jet of combustion products, which accelerates and heats the sprayed powder. The coating was formed at a distance of $50 \mathrm{~mm}$. The number of passes was equal to 4 . Powder heating and acceleration nozzle length was $300 \mathrm{~mm}$, diameter was $16 \mathrm{~mm}$. The composition and consumption of components of the flammable gas mixture are shown in Table 1.

Table 1.

Gas consumption rates.

\begin{tabular}{c|c|c}
\hline \multicolumn{3}{c}{ Gas consumption, $\mathrm{m}^{3} / \mathrm{h}$} \\
\hline \multirow{4}{*}{1 chamber } & $\mathrm{O}_{2}$ & 3.3 \\
\cline { 2 - 3 } & air & 1.1 \\
\cline { 2 - 3 } & $\mathrm{C}_{3} \mathrm{H}_{8}+\mathrm{C}_{4} \mathrm{H}_{10}$ & 0.7 \\
\hline \multirow{2}{*}{2 chamber } & $\mathrm{O}_{2}$ & 3 \\
\cline { 2 - 3 } & air & 1 \\
\cline { 2 - 3 } & $\mathrm{C}_{3} \mathrm{H}_{8}+\mathrm{C}_{4} \mathrm{H}_{10}$ & 0.67 \\
\hline Pit & air & 1 \\
\hline
\end{tabular}

Part of the coated samples was treated by pulsed plasma at the installation "Impulse-6". Feature of the used pulsed coaxial plasma generator is the possibility of switching of electric current by ionized gas region behind the detonation wave front [11]. This makes it possible to generate the pulsed plasma with a frequency of $1-4 \mathrm{~Hz}$ and energy up to $7 \mathrm{~kJ}$. As a result, the surface experiences a multiple pulsed thermal impact. Heat flux power density is $10^{4} \ldots 10^{6} \mathrm{~W} / \mathrm{cm}^{2}$. It is also possible to introduce a complex of different alloying elements into the plasma. PPT provides rapid heating (heating time $10^{-3} \ldots 10^{-4} \mathrm{~s}$ ) of surface layer and its subsequent intensive cooling by heat removal into the volume of the product. High rate (up to $107 \mathrm{~K} / \mathrm{s}$ ) of melting and crystallization of surface layers promote the formation of a fine crystal structure and high density of dislocations. Impulse thermal influence, elastoplastic deformation of processed material structure in combination with electromagnetic influence due to pulse current flow (up to 10 $\mathrm{kA} / \mathrm{cm}^{2}$ ) through the processed surface layers intensifies various physical and chemical processes. Parameters of pulse-plasma treatment are given in Table 2. 
Table 2.

PPT parameters.

\begin{tabular}{l|c|c}
\hline \multicolumn{1}{c|}{ Parameter } & Sample 1 & Sample 2 \\
\hline Voltage at the capacitor battery terminals $(\mathrm{V})$ & \multicolumn{2}{c}{3200} \\
\hline Capacitor battery capacity of discharge circuit $(\mu \mathrm{F})$ & \multicolumn{2}{|c}{360} \\
\hline Inductance of discharge circuit $(\mu \mathrm{HN})$ & \multicolumn{2}{|c}{30} \\
\hline Plasma pulse frequency $(\mathrm{Hz})$ & \multicolumn{2}{|c}{3.2} \\
\hline $\begin{array}{l}\text { Speed of plasma gun moving relative to the item } \\
(\mathrm{mm} / \mathrm{sec})\end{array}$ & 50 & 60 \\
\hline Distance to surface, $\mathrm{h}(\mathrm{mm})$ & \\
\hline
\end{tabular}

The phase composition of coatings was studied by means of traditional methods of X-ray diffraction (XRD) using X'PertPro diffractometer, namely the analysis of angle positions, intensities and profiles of diffraction reflections. Measurement of microhardness of samples was carried out according to GOST 9450-76 (ASTM E384-11) on Metolab 502 microhardness tester, at loads on an indenter $\mathrm{P}=0.1$ $\mathrm{N}$ and exposure time $10 \mathrm{sec}$. Nanoindentation was performed on a NanoScan4D nanohardness tester, according to GOST R 8.748-2011, at a load of $100 \mathrm{mN}$. Young's module and hardness were determined by the method of Oliver and Farr. Surface roughness of the coatings $R_{a}$ was evaluated using profilometer model 130.

\section{Results and discussion}

Figure 2 presents the results of roughness measurements and obtained profilograms of $\mathrm{Fe}-\mathrm{TiB}_{2}-\mathrm{CrB}_{2}$ coatings.
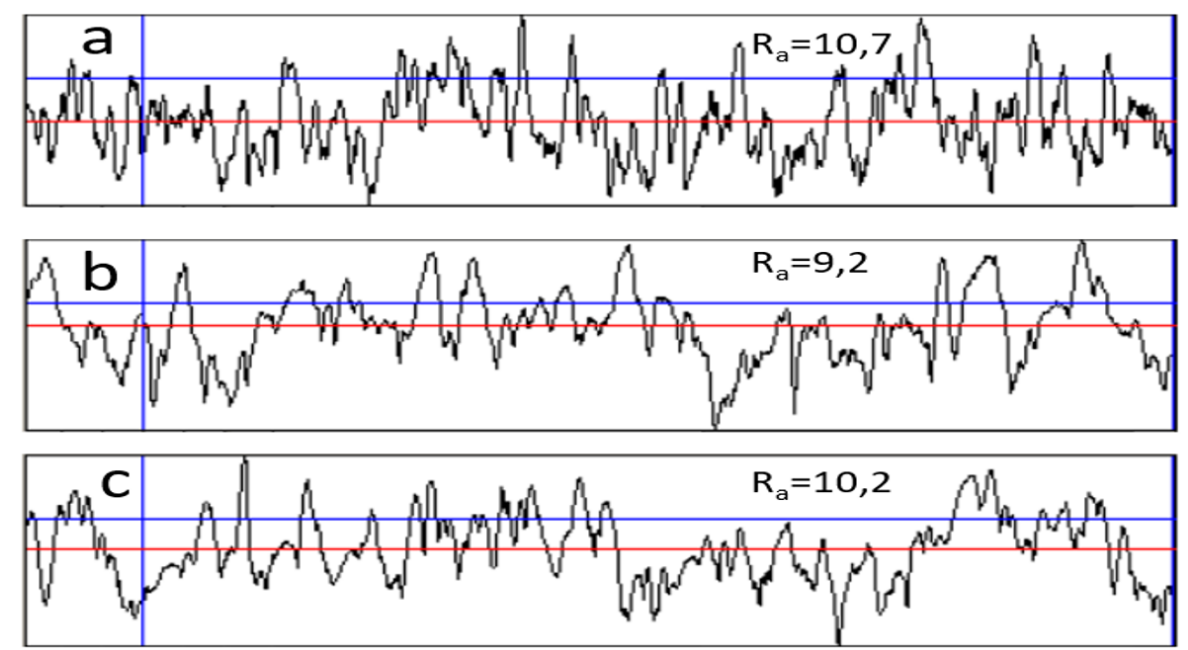

Figure 2. Profilograms and surface roughness of $\mathrm{Fe}-\mathrm{TiB}_{2}-\mathrm{CrB}_{2}$ coatings before (a) and after plasma treatment (b-50 $\mathrm{mm}),(\mathrm{c}-60 \mathrm{~mm})$.

The surfaces of the coatings have an inhomogeneous structure. The Ra value, which is the arithmetic mean deviation of the profile, was chosen as the main parameter for assessing the surface roughness of the coatings. The roughness parameter of the coatings obtained before the plasma treatment has values 
$R_{a}=10.7 \mu \mathrm{m}$. The coatings after plasma treatment showed a slight decrease in roughness: for the coatings with a distance to the surface of $50 \mathrm{~mm}-R_{a}=9.2 \mu \mathrm{m}$, and with a distance to the surface of $60 \mathrm{~mm}-R_{a}=10.2 \mu \mathrm{m}$. The decrease in this value is associated with the treatment of the coating surface with a plasma jet, which melts the protruding particles [14].

Figure 3 shows the radiographs of the coating surface before and after pulseplasma treatment. It can be seen from the figure that coatings the reflexes of $\mathrm{CrB}_{2}$ and $\mathrm{TiB}_{2}$ and $\mathrm{Fe}_{4} \mathrm{O}_{8}$ phases are observed after the PPT in the diffractogram of $\mathrm{Fe}-\mathrm{TiB}_{2}-\mathrm{CrB}_{2}$.

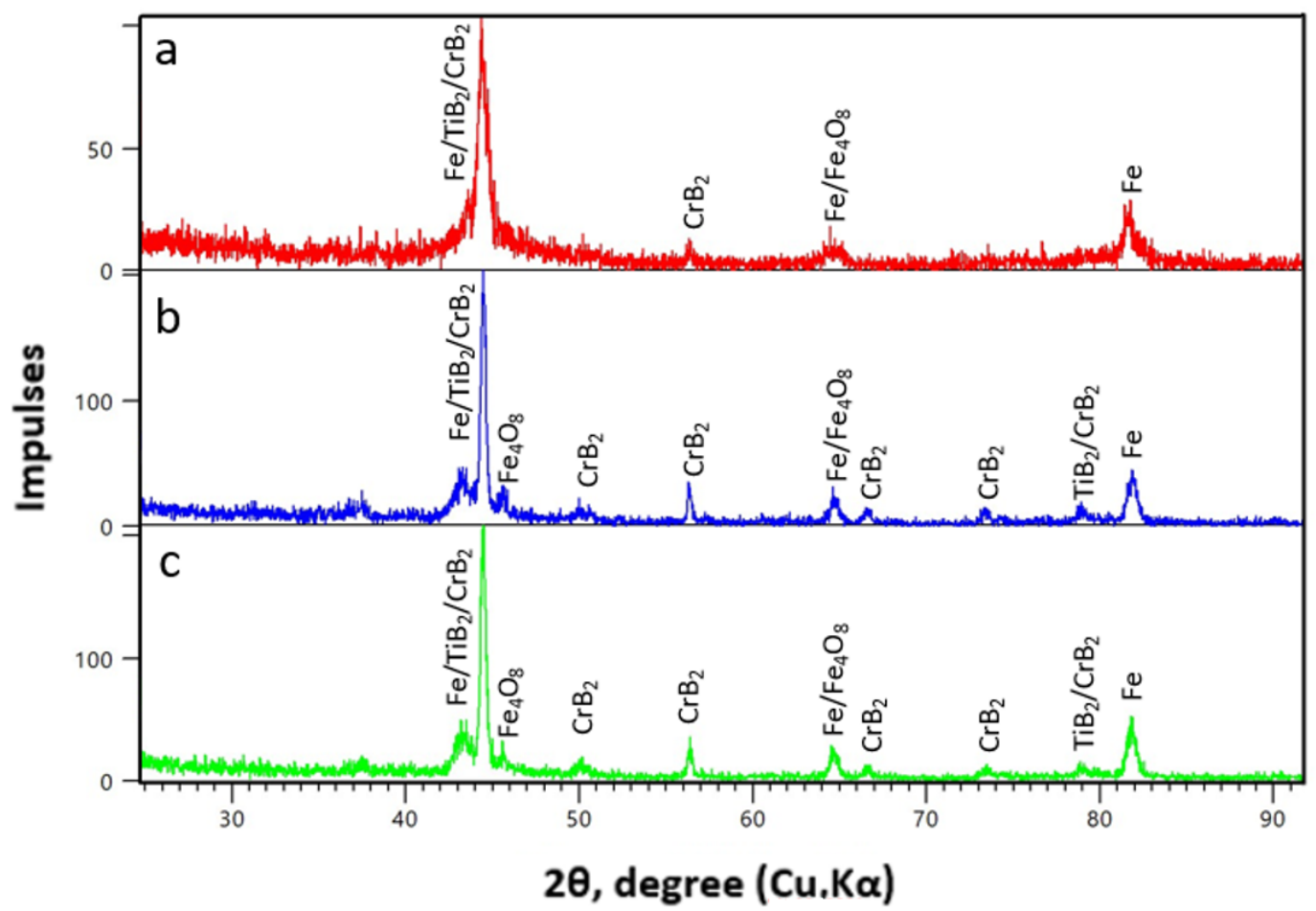

Figure 3. X-ray pictures of $\mathrm{Fe}-\mathrm{TiB}_{2}-\mathrm{CrB}_{2}$ coatings before (a) and after pulse-plasma treatment (b-50 mm, c-60 mm).

The microhardness of $\mathrm{Fe}-\mathrm{TiB}_{2}-\mathrm{CrB}_{2}$ coatings is shown in Figure 4. An increase in the microhardness of $\mathrm{Fe}-\mathrm{TiB}_{2}-\mathrm{CrB}_{2}$ coatings is observed after the PPT. PPT was carried out at distances to the surface $h=50$ and $h=60 \mathrm{~mm}$. Microhardness of coatings before pulse plasma processing made $\approx 7.4 \mathrm{GPa}$ (Figure $4 \mathrm{a}$ ). It can be seen that the microhardness value increases after the PPT (Figure $4(\mathrm{~b}, \mathrm{c})$ ) and is under $\mathrm{h}=50 \mathrm{~mm} \approx 11.3 \mathrm{GPa}$ and under $\mathrm{h}=60 \mathrm{~mm} \approx 11.9 \mathrm{GPa}$.

Figure 5 shows the microhardness distribution graph for the thickness of the coatings after pulse plasma treatment. The graph of microhardness dependence on depth of $\mathrm{Fe}-\mathrm{TiB}_{2}-\mathrm{CrB}_{2}$ coating shows microhardness distribution for two samples: coating near the transition layer has greater microhardness value after PPT at $50 \mathrm{~mm}$, in contrast to the near-surface layers; and coating has more uniform microhardness distribution after PPT at $60 \mathrm{~mm}$.

The change in hardness is explained by changes in the concentration of $\mathrm{TiB}_{2}$ and $\mathrm{CrB}_{2}$ particles in the Fe matrix [15] for different samples. It follows from this profile that the hardness value is affected by the solid phase content and its distribution in the coating. It also indicates that hardness decreases rapidly 


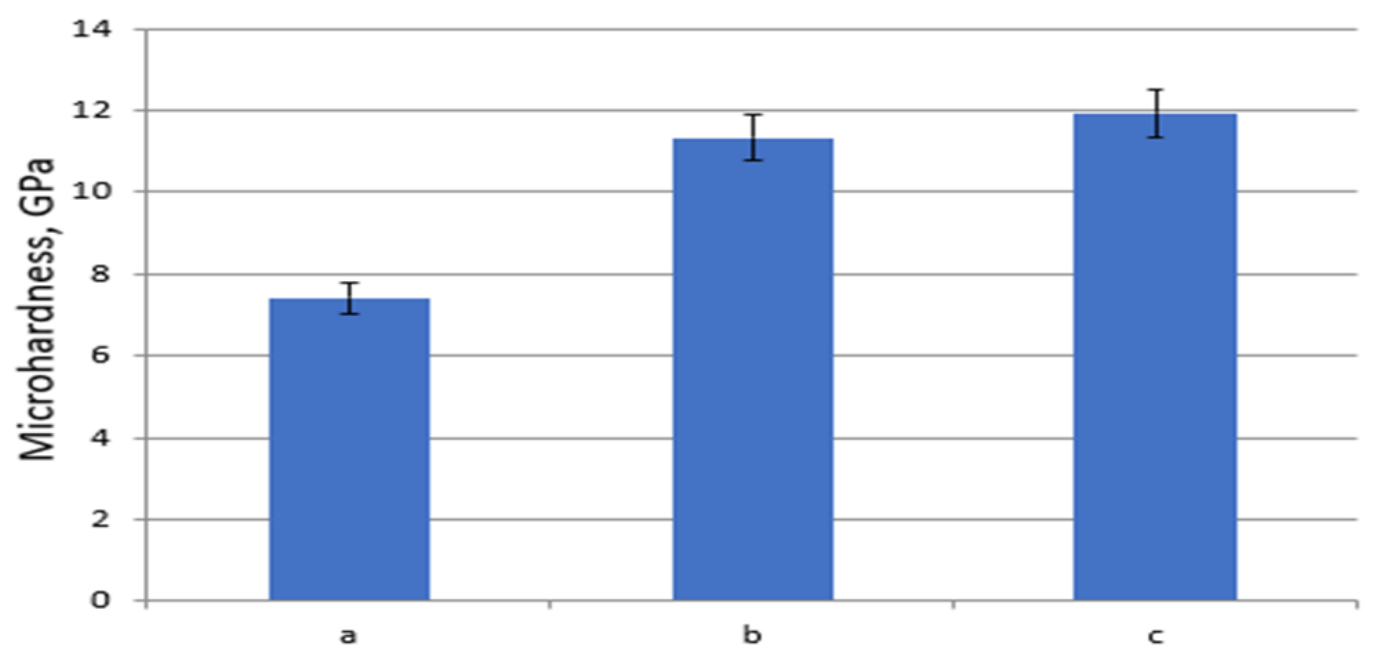

Figure 4. Microhardness of the coating surface.

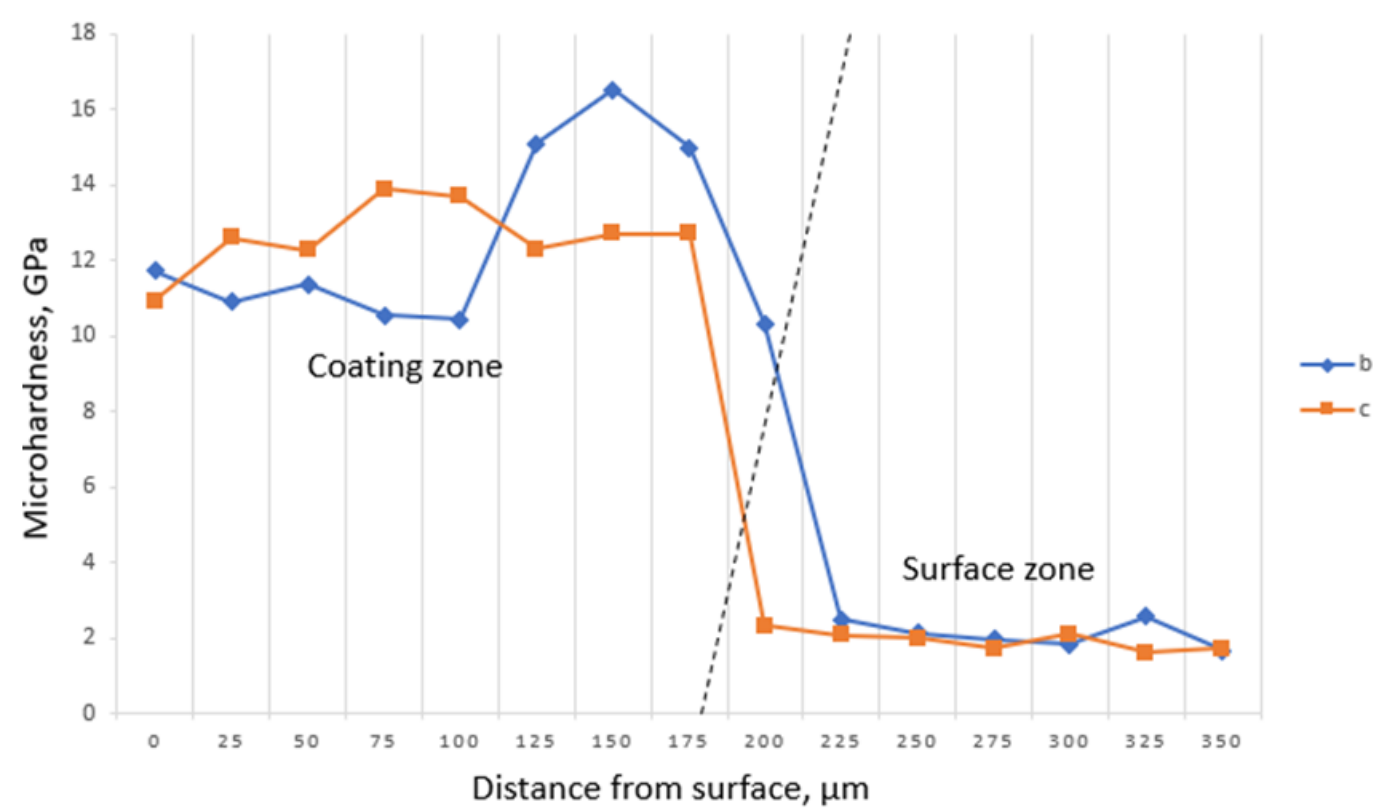

Figure 5. Graph of hardness distribution by depth of $\mathrm{Fe}^{-}-\mathrm{TiB}_{2}-\mathrm{CrB}_{2}$ coatings after pulse-plasma treatment (b-50 mm, c-60 mm).

near the interface due to dilution of soft metal particles; elemental EDS analysis (Figure 6) confirmed the case of dilution.

Also, the high hardness of $\mathrm{Fe}-\mathrm{TiB}_{2}-\mathrm{CrB}_{2}$ coatings after pulsed plasma treatment is explained by phase transformations. It was found on the bases of X-ray diffraction analysis that the increased hardness of the coatings after pulsedplasma hardening can be associated with an increase in the number of boride particles $\left(\mathrm{TiB}_{2}\right.$ and $\left.\mathrm{CrB}_{2}\right)$ [16].

The elemental composition of the coatings and the base material was determined by EDS analysis (Figure 6). It can be seen from the obtained data that the chemical composition of the coating is preserved after detonation spraying. 

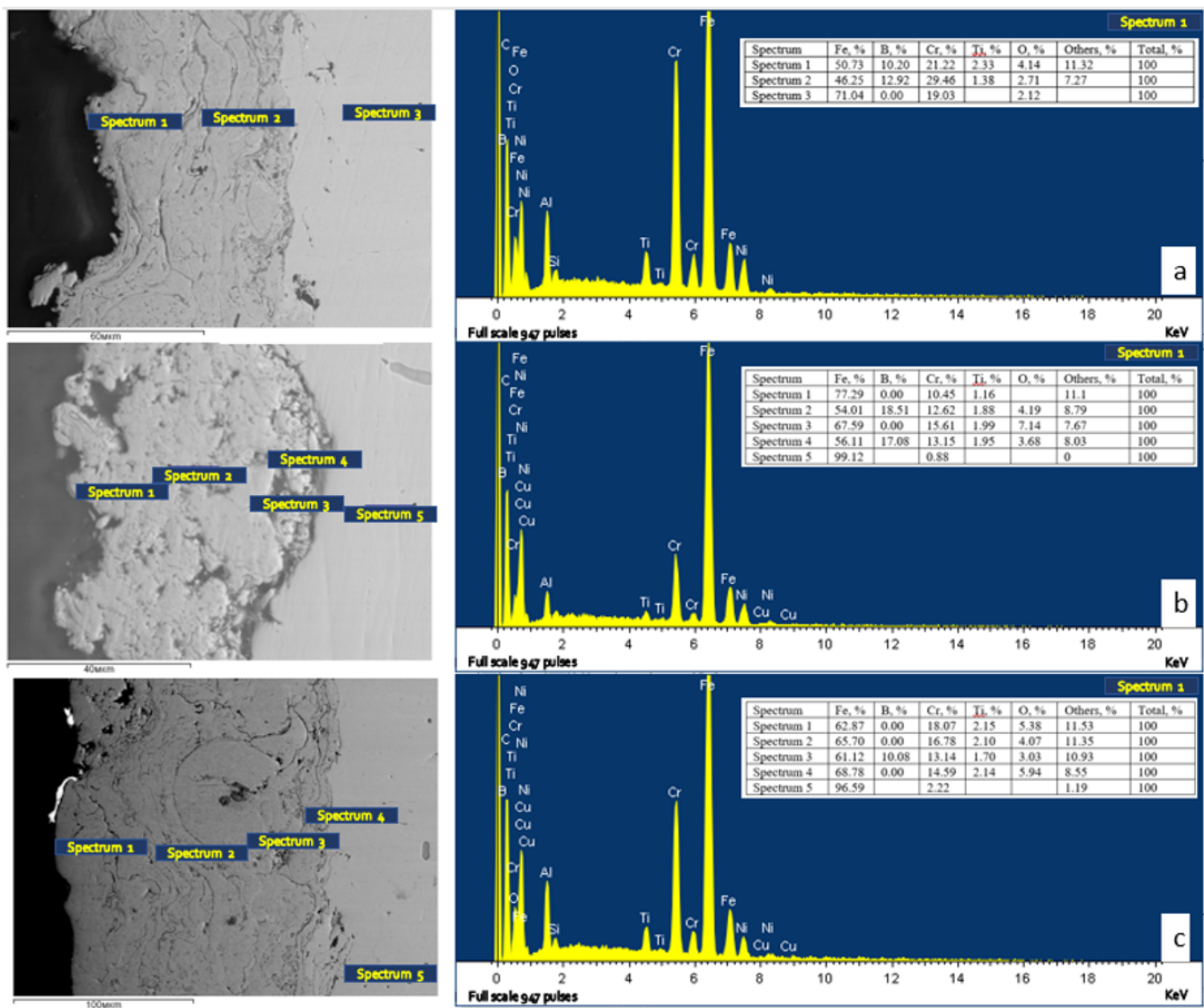

Figure 6. The elemental analysis of $\mathrm{Fe}-\mathrm{TiB}_{2}-\mathrm{CrB}_{2}$ coatings by spectra before (a) and after plasma treatment at the range of $50 \mathrm{~mm}(\mathrm{~b})$ and $60 \mathrm{~mm}(\mathrm{c})$.

\section{Conclusion}

On the bases of the experimental obtained data and their analysis, the following conclusions were drawn: $\mathrm{Fe}-\mathrm{TiB}_{2}-\mathrm{CrB}_{2}$ coating on the bases of Fe reinforced by $\mathrm{TiB}_{2}$ and $\mathrm{CrB}_{2}$ was successfully obtained by the method of detonation sputtering and processed by pulse-plasma treatment method. It was determined that the hardness of the investigated coatings is in the range from $\approx 10.3 \mathrm{GPa}$ to $\approx 16.5$ GPa after pulse-plasma treatment. The change of microhardness is explained by the change of concentration of $\mathrm{TiB}_{2}$ and $\mathrm{CrB}_{2}$ solid particles in Fe matrix for different samples.

As a result, PPT can be recommended as a method of improving the complex of physical-mechanical properties of pre-sprayed gas-thermal coatings.

\section{Acknowledgments}

This paper was performed within the grant financing of scientific research of the Committee of Science of the Ministry of Education and Science of the Republic of Kazakhstan. Grant AP08957765. 


\section{References}

[1] O.V. Maksakova et al., Materials Research Express 6(10) (2019) 106438.

[2] B. Rakhadilov et al., Coatings 11(2) (2021) 1-14, 218.

[3] V.E. Panarin et al., Aviacionno-kosmicheskaya tekhnika i tekhnologiya 6 (2016) 15-20. (in Russian)

[4] M. Pashechko et al., Lubelskie Towarzystwo Naukowe (2001) 379-387.

[5] M. Pashechko et al., Zeszyty Budowa Maszyn (2009) 125-127.

[6] A.K. Shurin et al., Metallovedenie i termicheskaja obrabotka metallov 8 (1977) 53-55. (in Russian)

[7] M.V. Kindrachuk et al., Metallovedenie i obrabotka metallov 1 (1995) 38-45. (in Russian)

[8] B. Dastan et al., Key Engineering Materials 839 (2020) 137-143.

[9] Lei Guo et al., Journal of Advanced Ceramics 9(2) (2020) 232-242.

[10] M. Skakov et al., Key Engineering Materials 531-532 (2013) 627-631.

[11] Yu.N. Tyurin and O.V. Kolisnichenko, The Open Surface Science Journal 1 (2009) 13-19.

[12] M.G. Kovaleva et al., Journal of Nano- and Electronic Physics 10(6) (2018) 06035-1-06035-4.

[13] D.N. Kakimzhanov et al., Eurasian Journal of Physics and Functional Materials 5(1) (2021) 45-51.

[14] V.A. Okovityj et al., Vestnik Belorusskogo nacional'nogo tekhnicheskogo universiteta: nauchno-tekhnicheskij zhurnal 5 (2009) 38-43. (in Russian)

[15] A. Kumar et al., Materials Today: Proceedings 39(4) (2021) 1291-1295.

[16] V.E. Panarin, Aviacionno-kosmicheskaya tekhnika i tekhnologiya 8 (2014)

108-112. (in Russian) 